\title{
Aplicação do jogo eletrônico educativo Calangos na escola: Coleta de eventos e Scoreboard Crystal Silva Campos ${ }^{1}$; Angelo Conrado Loula ${ }^{2}$;
}

\author{
1. Bolsista PIBIC/CNPq, Graduando em Engenharia da Computação, Universidade Estadual de Feira de Santana, e- \\ mail: campos537@ hotmail.com \\ 2. Orientador, Departamento de Exatas, Universidade Estadual de Feira de Santana, e-mail: angelocl@ uefs.br
}

PALAVRAS-CHAVE: jogo eletrônico educativo; ensino de biologia; ferramenta de INTRODUÇÃO ensino-aprendizado.

O mercado de jogos eletrônicos envolve uma comunidade crescente de usuários e somente no Brasil foi estimado em 61 milhões de jogadores (Fleury, Nakano e Cordeiro, 2014). Dessa forma, pelo fato da maioria dos usuários serem crianças e adolescente na faixa de 12 a 19 anos (IBOPE, 2012) surge assim a possibilidade de transformar esse mercado de entretenimento em um modo de ajudar na educação dos mesmos. De fato, jogos educativos eletrônicos tem demonstrado ser facilitador do ensino e aprendizagem (Giannakos, 2013).

Um dos jogos eletrônicos educativos disponíveis hoje é o jogo Calangos (Loula et al., 2014). Trata-se de um jogo de simulação e ação que funciona como uma ferramenta de suporte de ensino e aprendizado da ecologia. O jogo coloca o usuário no controle de um lagarto, podendo ser criado ou escolhido entre 3 espécies(Tropidurus psammonastes, Cnemidophorussp. Nov., and Eurolophosaurus divaricatus), após isso o jogador tem que sobreviver simulando as relações ecológicas do lagarto, tais como a necessidade de se alimentar, controlar sua temperatura e se reproduzir. Com o intuito que ficasse mais simples a interpretação das informações mostradas no jogo foram criados gráficos que mostram informações do largarto tais como temperatura, hidratação, energia, facilitando os alunos que quisessem comparar informações dadas rapidamente pelo jogo.

O jogo Calangos tem sido avaliado em aplicações no ensino médio de uma escola pública localizada em Feira de Santana e agora está sendo utilizado em uma escola na Colômbia. Por meio da demanda de uso na escola, o jogo tem sido aperfeiçoado a partir de demandas apontadas pela equipe do projeto.

Dessa forma, o objetivo principal deste resumo se dá diante de novas demandas visando melhorar a jogabilidade de modo a facilitar a interpretação das informações disponíveis no Calangos por parte das crianças e adolescente que o utilizam em sala de aula. Para facilitar essa análise de informações surgiu a necessidade de criação da coleta de eventos do personagem, que podem ser identificados como o ato do lagarto se movimentar, se alimentar e entrar ou sair da sombra, que funcionaria armazenando cada ação do jogador de modo a desenhar nos gráficos as ações tomadas. Além disso, de modo a também incentivar o aprendizado dos alunos, se decidiu criar uma tabela de pontuação, que funcionaria didaticamente como um incentivo para que os alunos realmente pudessem aprender a melhor forma de sobrevivência do lagarto, gerando assim certa competição entre os mesmos.

\section{MATERIAL E MÉTODOS}

Calangos é implementado com a utilização do motor de jogos Panda3D (panda3d.org) e a linguagem de programação $\mathrm{C}++$. $\mathrm{O}$ motor de jogos Panda3D é uma biblioteca composta de sub-rotinas que são responsáveis por funcionalidades básicas de qualquer jogo, como renderização, controle de câmera e gerência de evento. As novas funcionalidades serão implementadas nessa mesma linguagem. 
Calangos continuará seguindo as etapas de desenvolvimento de um software evolucionário. Os requisitos do jogo serão obtidos através de conversas com os clientes, ou seja, professores e alunos. É, portanto, fundamental a interação entre desenvolvedores e jogadores. Sobre a implementação, o jogo será desenvolvido constantemente, por meio de novas funcionalidades, manutenção ou correção de erros.

Neste plano de trabalho, se continuou a coleta dos dados, buscando registrar eventos do jogo para complementação dos gráficos que estão disponíveis- como o gráfico de temperatura ambiente ou temperatura do solo. Os eventos de interesse envolvem movimento do jogador (andar, correr, parar), eventos de predação, eventos de comer alimentos, eventos de entrada e saída da sombra, dentre outros. Após discussões com os professores responsáveis pela aplicação do jogo, percebeu-se a necessidade de realizar adaptações nos gráficos, pois eles são uma forma importante de representar e relacionar as ações do lagarto e fenômenos naturais ocorridos durante o jogo, além de ser conteúdo de estudo ao longo do Ensino Médio. Além disso, também decidiu-se pela criação de um scoreboard (quadro de pontuação) para armazenar a pontuação do jogador, aumentando o desafio do jogo e a motivação do mesmo para atingir resultados melhores.

\section{RESULTADOS E DISCUSSÃO}

Durante o período de iniciação científica inicialmente foi realizado o levantamento de quais seriam os eventos do jogo que seriam posteriormente coletados e exibidos superpostos aos gráficos já disponíveis para o usuário. Os eventos selecionados seriam: entrada e saída da sombra, alimentação e movimento (andar, correr, parar) do lagarto.

Após isso se iniciou a etapa de desenvolvimento da coleta e registro desses eventos previamente definidos, desta forma armazenando sempre que o usuário realizasse alguma das ações descritas anteriormente. Em seguida, foi realizado o planejamento de como exibir essas informações para o usuário, ficando decidida a utilização de barras verticais coloridas e legenda. A figura 1 mostra como funciona a exibição dos eventos nos gráficos.

Após o término da coleta e exibição dos eventos realizados pelo jogador, passou-se ao planejamento da implementação do scoreboard. A primeira funcionalidade seria uma interface para obtenção do nome do jogador. Dessa forma, foi implementada antes do carregamento do jogo uma tela para que o usuário pudesse colocar o seu nome. A figura 2 mostra a tela em que o usuário insere o seu nome.

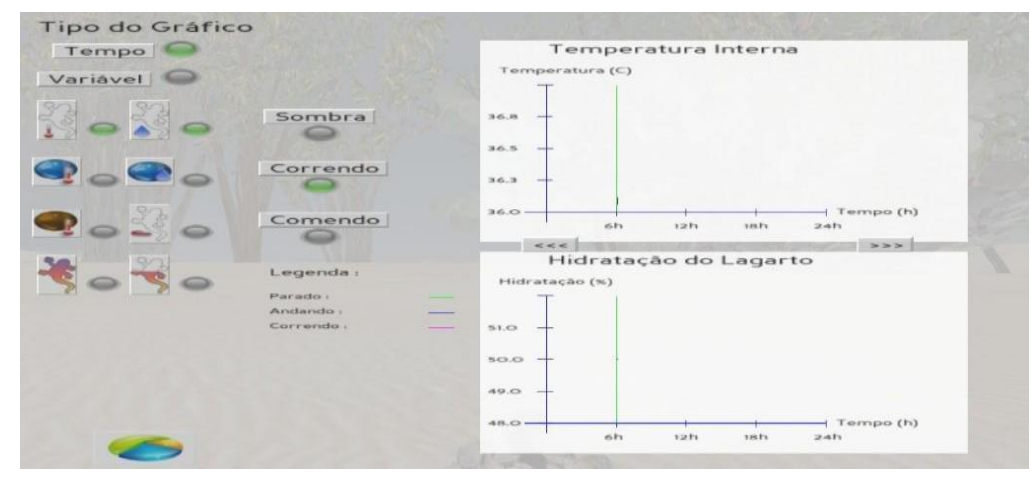

Figura 1. Evento desenhado indicando que o lagarto estava parado em dado momento 


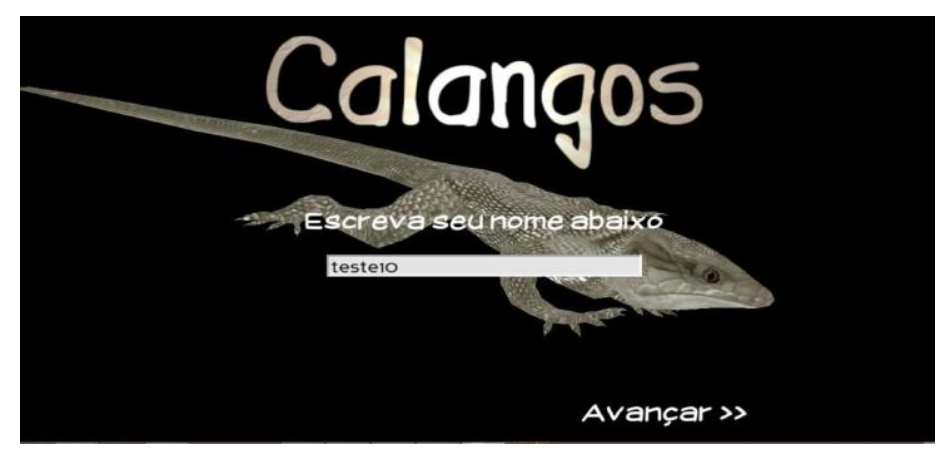

Figura 2. Interface para o jogador inserir o nome desejado

Com a tela para a obtenção do nome pronta, passou-se à coleta das informações necessárias para a criação da tabela de pontuação. Essas informações seriam a quantidade de ovos produzidos pelo jogador diante do êxito entre a reprodução do lagarto e a quantidade de estrelas conseguidas pelo mesmo, provindas das realizações alcançadas. Dessa forma, foram armazenados os nomes dos jogadores juntamente com suas pontuações durante sua sessão no jogo. Após isso, foi implementada a etapa de exibição para o usuário em que ele poderia ver os nomes dos 10 melhores jogadores e suas pontuações, devidamente ordenadas primeiro pela quantidade de ovos e depois pela quantidade de estrelas, com o recurso de clicar no nome e exibir a tela de detalhamento das realizações alcançadas pelo jogador. Todos esses armazenamentos (nomes e informações de pontuação) foram realizados em arquivos de pré-configuração que a manipulação é realizada pela própria engine Panda3D. A figura 3 mostra a tabela de pontuação implementada e a 4 mostra a tela de conquistas alcançadas pelo jogador.

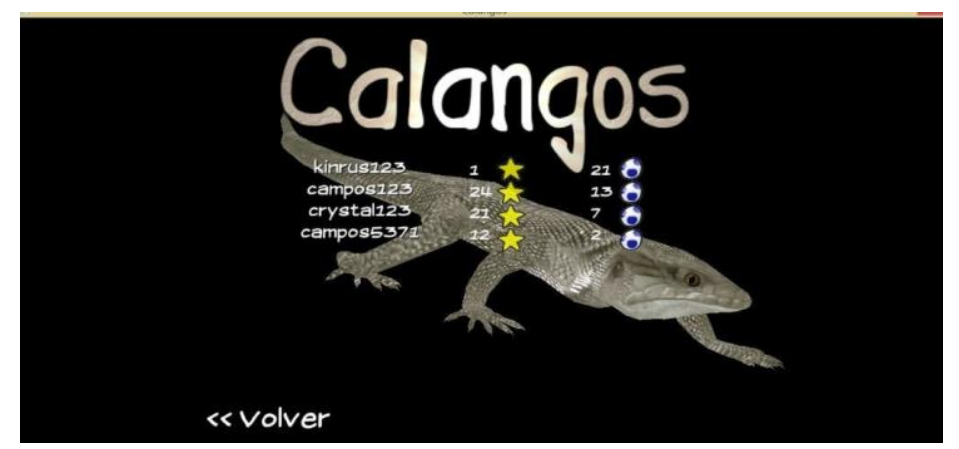

Figura 3. Tabela de pontuação devidamente ordenada priorizando a maior quantidade de ovos (sucesso na vida reprodutiva do lagarto)

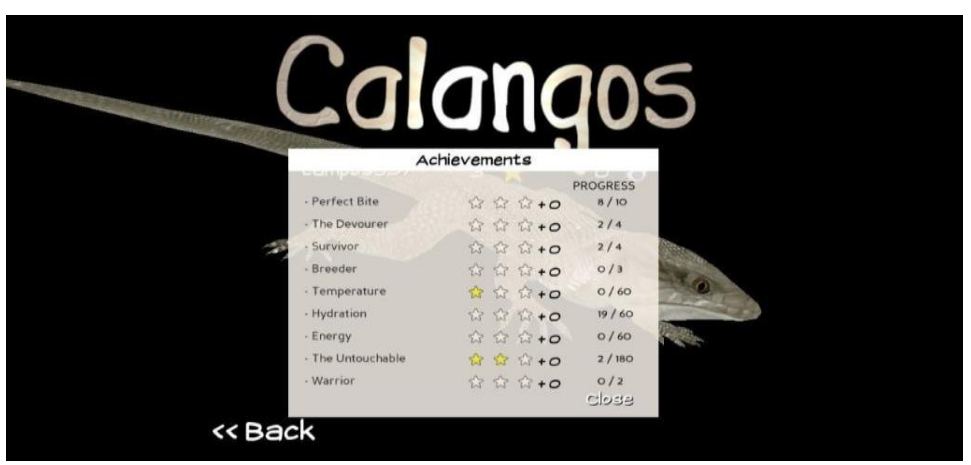

Figura 4. Tabela de conquistas alcançadas pelo jogador em conjunto com o progresso 
Com isso pôde-se concluir que as alterações realizadas no jogo Calangos possibilitaram uma grande melhora na facilidade de interpretação dos dados apresentados, pois além de gráficos o jogador agora tem a possibilidade de visualizar os eventos realizados pelo lagarto e assim identificar o porquê de certas mudanças na fisiologia do lagarto, tais como energia, temperatura e hidratação. Além disso, com a funcionalidade da tabela de pontuação incita uma maior competição entre os jogadores para conseguir maiores classificações e, consequentemente, estimulando-os a cada vez mais aprender sobre como os lagartos sobrevivem na caatinga.

\section{REFERÊNCIAS}

FLEURY A.; NAKANO D.; CORDEIRO J. H. D. 2014 [online]. Mapeamento da Indústria Brasileira e Global de Jogos Digitais. NPGT / Escola Politécnica/USP. Homepage:

http://www.abragames.org/uploads/5/6/8/0/56805537/mapeamento_da_industria_brasil eira_e_global_de_jogos_digitais.pdf

GIANNAKOS, M.N. 2013. Enjoy and learn with educational games: Examining factors affecting learning performance. Computers \& Education. 68: 429-439.

IBOPE. 2012 [on line]. Conheça as principais características de quem joga videogame no Brasil. Homepage: http://www.ibope.com.br/pt-br/noticias/Paginas/Conheca-ascaracteristicas-de-quem-joga-videogame-no-Brasil.aspx

LOULA, C.A.; CASTRO, N.L.; APOLINÁRIO, L. A.; ROCHA, P.L.B.; CARNEIRO, M.C.L.; REIS, V.P.G.S.; MACHADO, R.F.; SEPULVEDA, C.; EL-HANI, C.N. 2014. Modeling a Virtual World for the Educational Game Calangos. International Journal of Computer Games Technology 4: 1-14. 